1

2

3

4

5

6

7

8

9

10

11

12

13

14

15

16

17

18

19

Supplemental Material

\title{
Predictable patterns in stacking and distribution of channelized fluvial sand bodies linked to channel mobility and avulsion processes
}

Hiranya Sahoo, M. Royhan Gani, Nahid D. Gani, Gary J. Hampson, John A. Howell, Joep E.A. Storms, Allard W. Martinius, and Simon J. Buckley

\section{Three-dimensional (3-D) Mapping of Channelized Sand Bodies from Lidar}

\section{Data}

For 3-D sand-body mapping and width correction, step-by-step procedures have been detailed in Sahoo and Gani (2015). Here we present the salient features of those steps and justifications for them. The nearly vertical, sparsely vegetated exposures of cliff faces in the study area and minimal structural distortion of strata provide a clear contrast between sandstones and mudstones (e.g., Fig. S1).

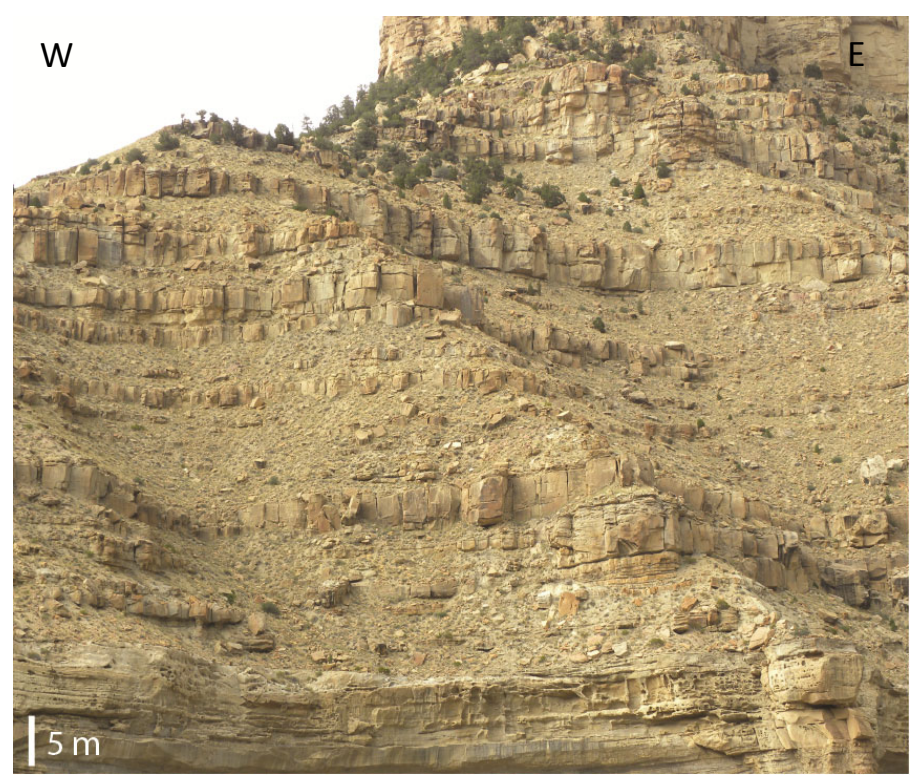

Figure S1. Example of cliff-face exposure in the study area. 
Acquisition and processing procedures of the lidar data were detailed in Rittersbacher et

21 al. (2013). Data were collected perpendicular to the outcrop faces, which ensured minimum

22 parallax error in capturing the preserved dimensions of the sedimentologic elements exposed

23 in the outcrop faces. The high resolution $(\sim 10 \mathrm{~cm})$ of the lidar data set (Fig. 2D) was

24 advantageous in distinguishing between sandstones and mudstones. As the 3-D lidar model is

25 fully georeferenced, it allowed both the vertical and lateral dimensions of individual

26 channelized sand bodies (henceforth "sand bodies") to be constrained, in addition to tracing

27 their continuity from one cliff-face to the next with precision. The resulting virtual outcrop

28 model has an areal extent of $\sim 5 \mathrm{~km} \times 5 \mathrm{~km}$ and thickness of $\sim 300 \mathrm{~m}$.

\subsection{Distinction between Single-Story and Multilateral Sand Bodies}

In our study, two fundamental types of sand bodies are identified: 1) a single-story sand

32 body comprises a single bar-macroform combined with a laterally adjacent channel-fill deposit,

33 and is characterized by a single basal surface of erosion (e.g., Potter, 1967); and 2) a multilateral

34 sand body comprises multiple channel-story sand bodies that are laterally amalgamated at the

35 same stratigraphic level, resulting in a composite basal surface of erosion (e.g., Potter, 1967;

36 Gibling, 2006). The distinction between single-story and multilateral sand bodies is made using

37 observations of stratal geometries in lidar (e.g., Figs. S2 and S3) and photographic data (Figs.

3C-3E; Fig. S10), supplemented by measured sections and paleocurrent data from accessible

39 outcrops in the study area and in nearby locations in the Wasatch Plateau outcrop belts

40 (Hampson et al., 2013; Sahoo and Gani, 2016; Sahoo et al., 2016). Single-story sand bodies and

41 stories within multilateral sand bodies have many similar characteristics: (1) their bases are 

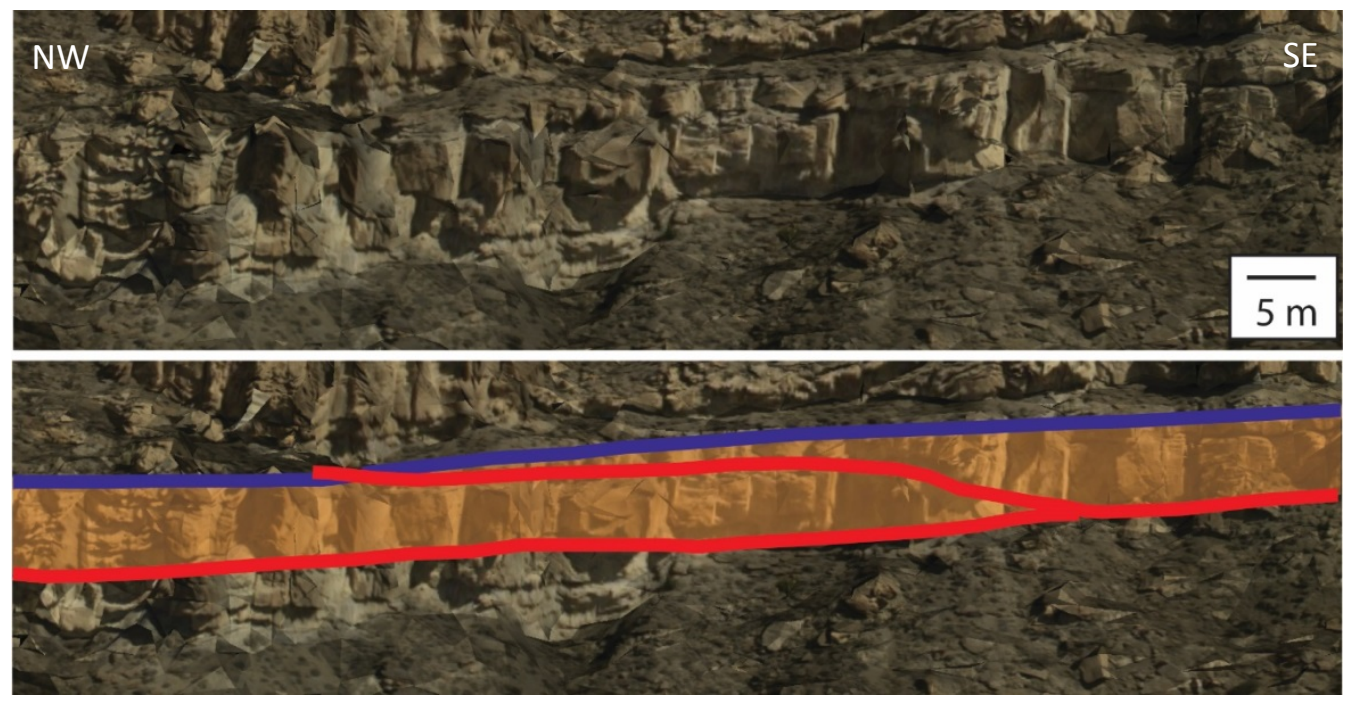

43 Figure S2. Multilateral sand body mapped in the lidar data (upper diagram: uninterpreted; lower

44 diagram: interpreted). Two single-story sand bodies are laterally amalgamated at the same stratigraphic

45 level. Red: channel-story base, blue: channel-story top.
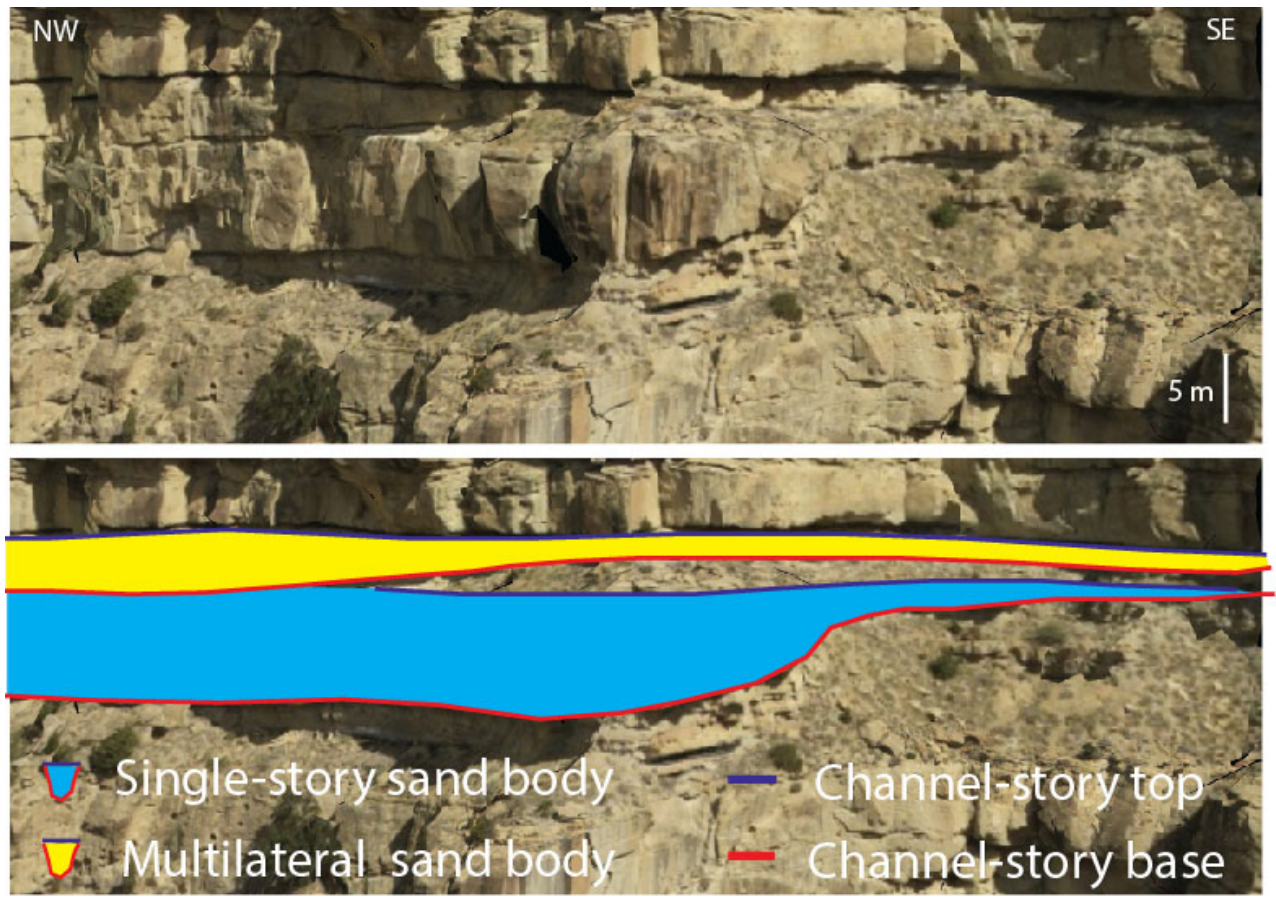

47 Figure S3. Lidar data (upper diagram: uninterpreted; lower diagram: interpreted) illustrating a

reoccupational stacking pattern in which a single-story sand body is overlain by a multilateral sand body.

49 For its photographic data, see Fig. 3C. Floodplain deposits are intercalated between underlying singlestory sand body and overlying multilateral sand body. 
51 marked by laterally discontinuous mudclast lags; (2) they comprise medium-grained sandstones

52 that grade upwards into fine-grained sandstones; (3) lateral-accretion sets at story margins are

53 common; (4) dune-scale cross-bedding is the predominant sedimentary structure; and (5)

54 siltstone and mudstone beds are absent (Hampson et al., 2013; Flood and Hampson, 2014;

55 Sahoo and Gani, 2016; Sahoo et al., 2016). In the 3-D lidar data set (e.g., Fig. S4; aided by

56 outcrop photos like Fig. S1), we mapped each channel-story individually by tracing their top-

57 bounding surface (blue color) and basal-erosion surface (pink color) (Figs. S5 and S6). Tracking the continuity of each single-story sand body, either isolated laterally or

59 forming part of a multilateral sand body, was performed across cliff faces using a combination

60 of observational constraints: (1) the top of the shallow-marine Star Point Formation, which

61 underlies the Blackhawk Formation (Fig. S4), is exposed throughout the study area and was

62 used as a datum surface from which the sand body altitude (i.e., $z$ value of the sand-body top,

63 after adjusting for the minor structural dip of $\sim 5^{0}$ towards the west) was monitored (Fig. S5); (2)

64 the thickness of each sand body was assumed to remain similar along its axis, in depositional-

65 dip orientation, over the extent of the study area ( $5 \mathrm{~km})$; and (3) we also used regionally

66 extensive coal zones within the study area (e.g., Axel Anderson, Blind Canyon, and Bear Canyon;

67 Fig. S4) as reference surfaces to check the stratigraphic positions of the sand bodies. 


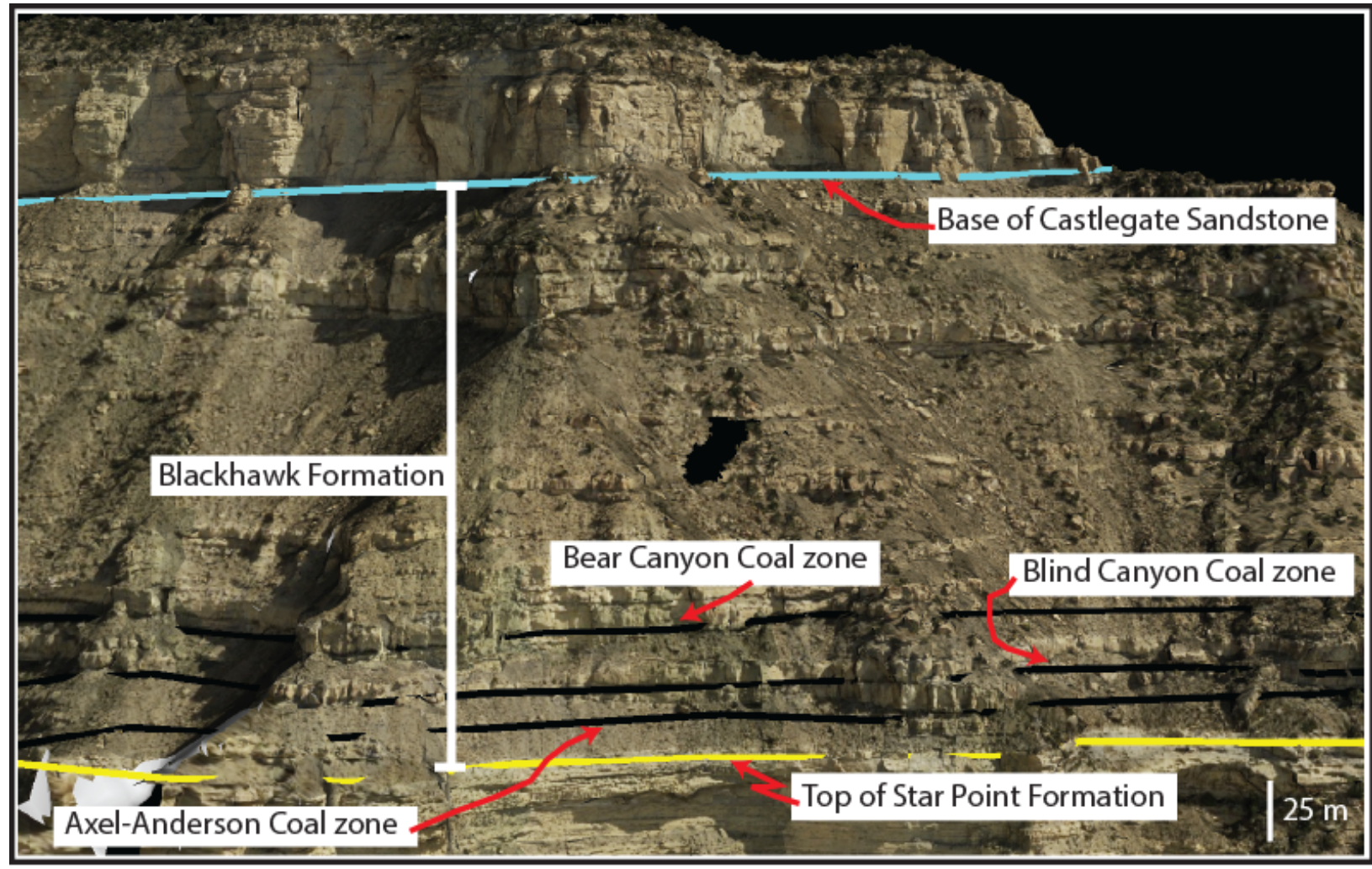

Figure S4. Lidar data showing the Star Point Formation, Blackhawk Formation, and Castlegate

Sandstone, along with three regionally extensive, well-defined coal zones in the Blackhawk Formation.

71 The data are from cliff face 6 shown in Figs. 2B-2D.

72

\subsection{Estimation of True Sand-body Width}

After mapping all sand bodies exposed at outcrop (Fig. S6), we undertook their width

correction. Sand bodies produced by channel migration are oriented along the mean flow

76 direction, instead of along the localized, variable azimuth of the paleochannel axis, such that

77 abundant paleoflow data were needed to delineate the correct sand body orientations. We

78 collected paleoflow data from lateral-accretion surfaces, dune and ripple cross-stratification in

79 the Blackhawk Formation $(n=236)$ from cliff faces 1,2 and 6 (Fig. 2). These data were grouped

80 by stratigraphic position (lower, middle, and upper Blackhawk Formation; Fig. S7). We 
81 calculated the vector mean of paleocurrents for the entire data set (N050), as well as separately

82 for the lower (N047), middle (N057), and upper (N045) Blackhawk Formation (Fig. S7).

83

84

85

86

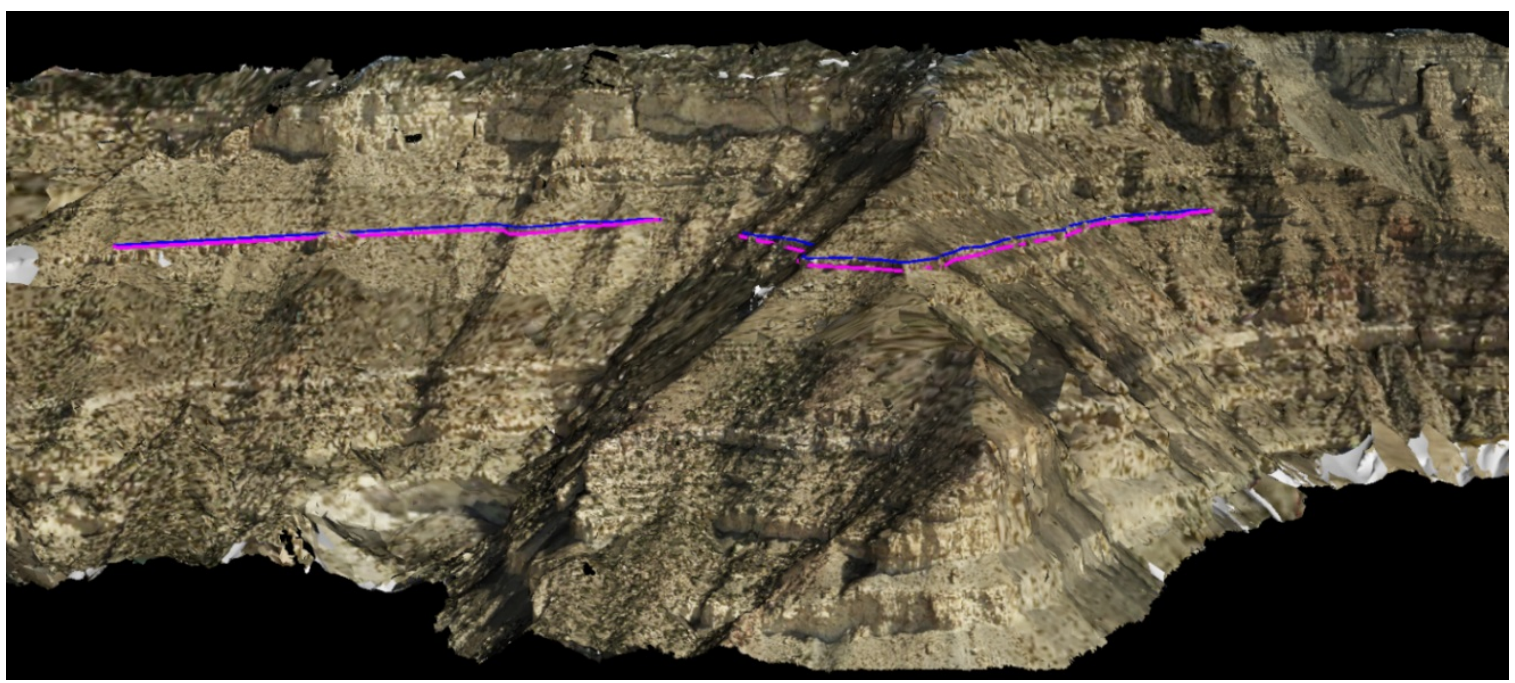

Figure S5. Examples of mapped sand-body base (pink color) and top (blue color) across the 3-D lidar data set. Outcrop is $483 \mathrm{~m}$ high. The data are from cliff faces 3 and 4 shown in Figs. 2B-2D.

87

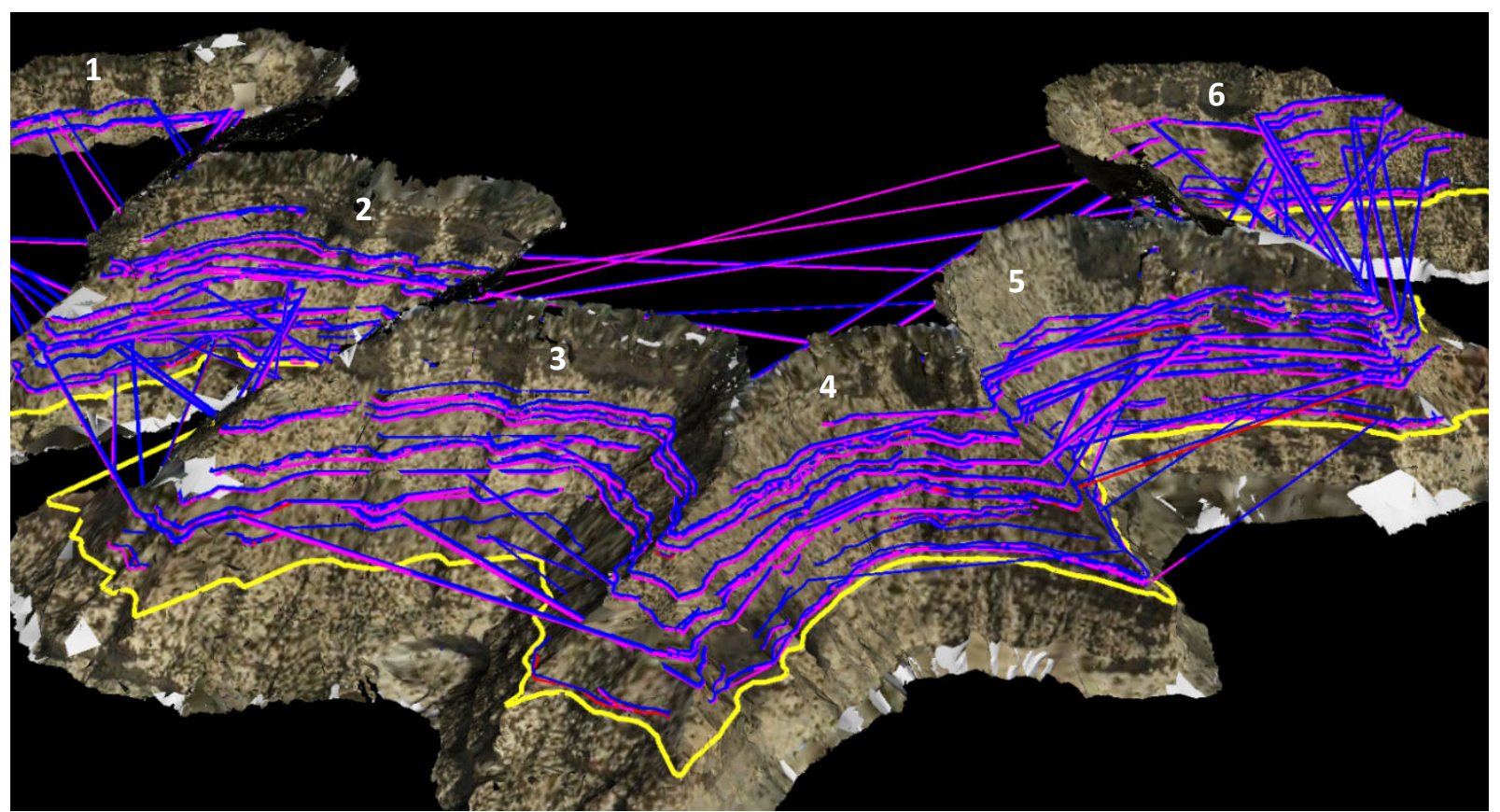

Figure S6. 3-D perspective view of tops and bases of mapped sand bodies in the lidar data set. Numbers denote cliff faces 1-6 shown in Figs. 2B-2D. 


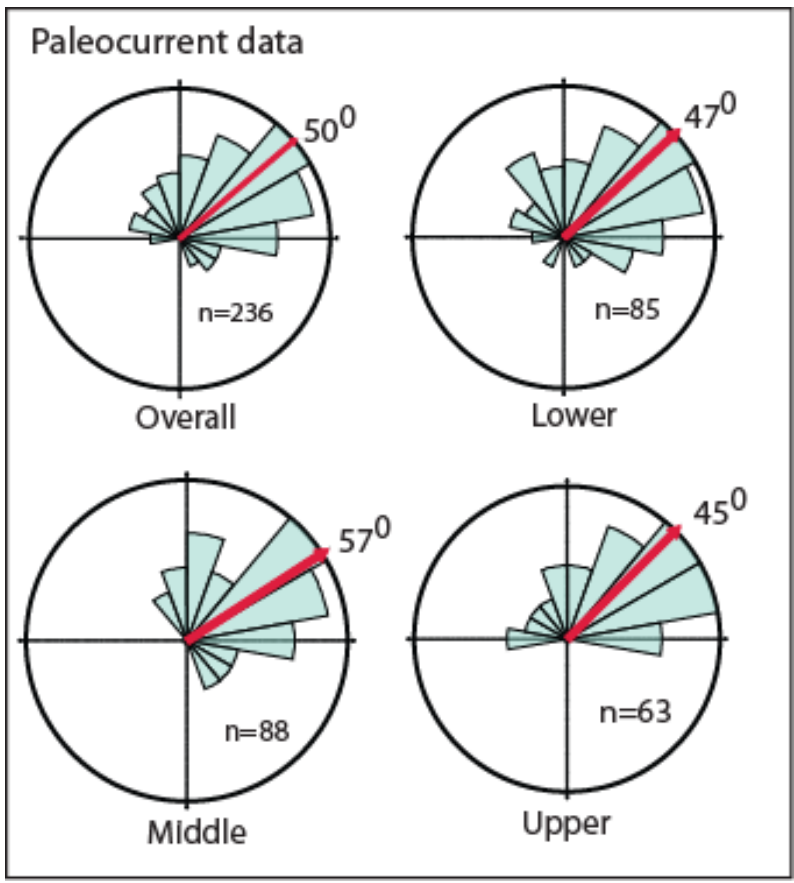

91 Figure S7. Paleocurrent data from the Blackhawk Formation in the study area.

As the overall vector mean (N050) shows consistency with the vector mean values of the

94 lower, middle, and upper Blackhawk Formation, we considered it to be a representative 95 paleocurrent value for the entire data set. Moreover, this vector mean value (N050) is also 96 broadly consistent with the regional paleoflow direction of the Blackhawk Formation (Hampson

97 et al., 2012; Rittersbacher et al., 2013). We carried out the width correction of mapped sand 98 bodies perpendicular to the paleoflow vector mean in the ArcMap platform (Fig. S8). The 99 procedure of sand body width-correction was performed on a projection plane aligned 100 perpendicular to the mean paleoflow direction (cf., Fabuel-Perez et al., 2009; Rittersbacher et 101 al., 2013).

As the depositional-dip extent of the study area is only $\sim 5 \mathrm{~km}$, it is reasonable to assume sand bodies to be linear and of uniform width at this scale (cf., Holbrook et al., 2006). With this assumption, all single-story and multilateral sand bodies with their corrected widths (Table S1) 
in order to investigate the stratigraphic organization of these sand bodies.

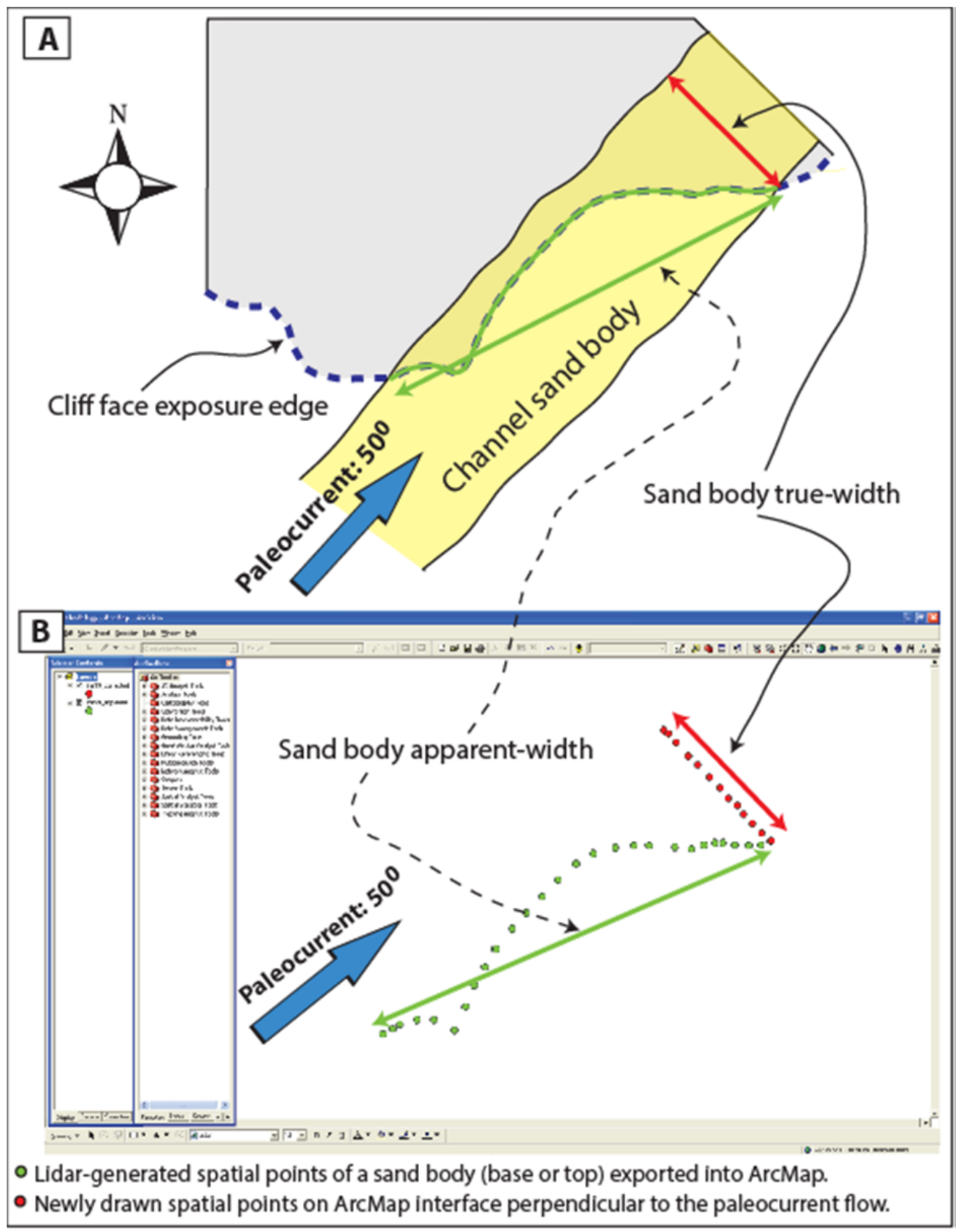

Figure S8. Width correction of sand body. A) The cliff face exposes the apparent width of a sand body instead of its true width. B) Points denoting the spatial position of the sand body in the lidar-generated outcrop model were imported to ArcGIS (green points). A new set of spatial points (red points) was 111 drawn perpendicular to the mean paleocurrent direction in order to calculate the true sand-body width. 
112 Table S1. Width-corrected dimensions of single-story and multilateral sand bodies that were 113 mapped in the study area. Mean values are listed in bold at the end of each column.

\section{Single-story}

Width $(m)$ Thickness $(m)$ Aspect ratio Width $(m)$ Thickness $(m)$

\begin{tabular}{|c|c|}
\hline 80 & \\
\hline 50 & \\
\hline 90 & \\
\hline 91 & \\
\hline 57 & \\
\hline 130 & \\
\hline 136 & \\
\hline 91 & \\
\hline 45 & \\
\hline 95 & \\
\hline 114 & \\
\hline 114 & \\
\hline 73 & \\
\hline 68 & \\
\hline 67 & \\
\hline 68 & \\
\hline 91 & \\
\hline 75 & \\
\hline 114 & \\
\hline 70 & \\
\hline 72 & \\
\hline 71 & \\
\hline 88 & \\
\hline 75 & \\
\hline 94 & \\
\hline 102 & \\
\hline 91 & \\
\hline 114 & \\
\hline 91 & \\
\hline 115 & \\
\hline 92 & \\
\hline 113 & \\
\hline 112 & \\
\hline 227 & \\
\hline
\end{tabular}

93

4
3
3
21
4
10
5
5
4
7
8
15
7
5
4
4
5
25
6
5
6
5
7
5
7
8
13
6
15
6
6
23
5
5
8
8
5
5
5
5
5
5

8

\section{Multilateral}

$17 \quad 704$

$30 \quad 795$

$4 \quad 204$

$14 \quad 273$

$13 \quad 682$

$27 \quad 295$

$18 \quad 886$

$11 \quad 932$

$14 \quad 280$

$14 \quad 375$

$8 \quad 523$

$10 \quad 295$

$14 \quad 841$

$17 \quad 227$

$17 \quad 454$

$18 \quad 909$

$3 \quad 227$

$19 \quad 432$

$14 \quad 1000$

$12 \quad 909$

$14 \quad 227$

$13 \quad 250$

$15 \quad 591$

$13 \quad 1204$

$13 \quad 772$

$7 \quad 273$

$19 \quad 886$

$6 \quad 318$

$19 \quad 841$

$15 \quad 386$

$5 \quad 295$

$22 \quad 863$

$45 \quad 273$

15

5

6

6

3

6

4

4

5

5

5

5

4

5

3

3

4
$3 \quad 151$

$5 \quad 182$

$4 \quad 57$

586

$4 \quad 250$

$4 \quad 227$

$\begin{array}{ll}4 & 57\end{array}$

$4 \quad 63$

$6 \quad 99$

$\begin{array}{ll}6 & 201\end{array}$

$6 \quad 129$

$4 \quad 68$

$5 \quad 177$

$4 \quad 80$

$5 \quad 168$

$5 \quad 77$

$4 \quad 74$

$5 \quad 173$

$5 \quad 55$

$5 \quad 159$

$7 \quad 101$

5200

$5 \quad 227$

$6 \quad 87$

$6 \quad 197$

1181

477

1181

1159

772

795

500

545

627

$5 \quad 95$

$7 \quad 169$

4290

$4 \quad 193$

988

$6 \quad 83$

$5 \quad 109$

$5 \quad 129$ 


\section{Ground-truthing of Lidar Data}

Both fine-grained floodplain deposits and sand bodies have been characterized at outcrop

116 using observations acquired by climbing cliff faces 1, 2 and 6 (Figs. 2B and 2C). Field

117 documentation included descriptions of lithology, grain size, sedimentary structures, and 118 paleoflow data. Latitude, longitude, and elevation values for these data were collected using a

119 handheld Tremble GPS of sub-meter accuracy. Dune-scale cross-set thickness data were 120 grouped for single-story and multilateral sand bodies. A subsurface core (EM-137C) that is 121 centrally located in the study area (Fig. 2C) was logged in detail (Fig. S9). Without core, detailed

122 characterization of floodplain deposits is challenging from outcrop data alone due to vegetation

123 and scree cover. Well-developed coal seams are developed preferentially in the lower part of 124 the Blackhawk Formation (Fig. 3A; Fig. S9), implying that a highly vegetated floodplain was 125 developed at certain times, generally coincident with regional shoreline transgression 126 (Hampson et al., 2012). Other types of floodplain deposit lack a pattern in their vertical 127 distribution (Fig. S9), as noted in other parts of the Wasatch Plateau outcrop belt (Flood and 128 Hampson, 2014). Single-story and multilateral sand bodies were interpreted in the field based 129 on their internal architecture (e.g., Figs. 3C-3E; Fig. S10C). 


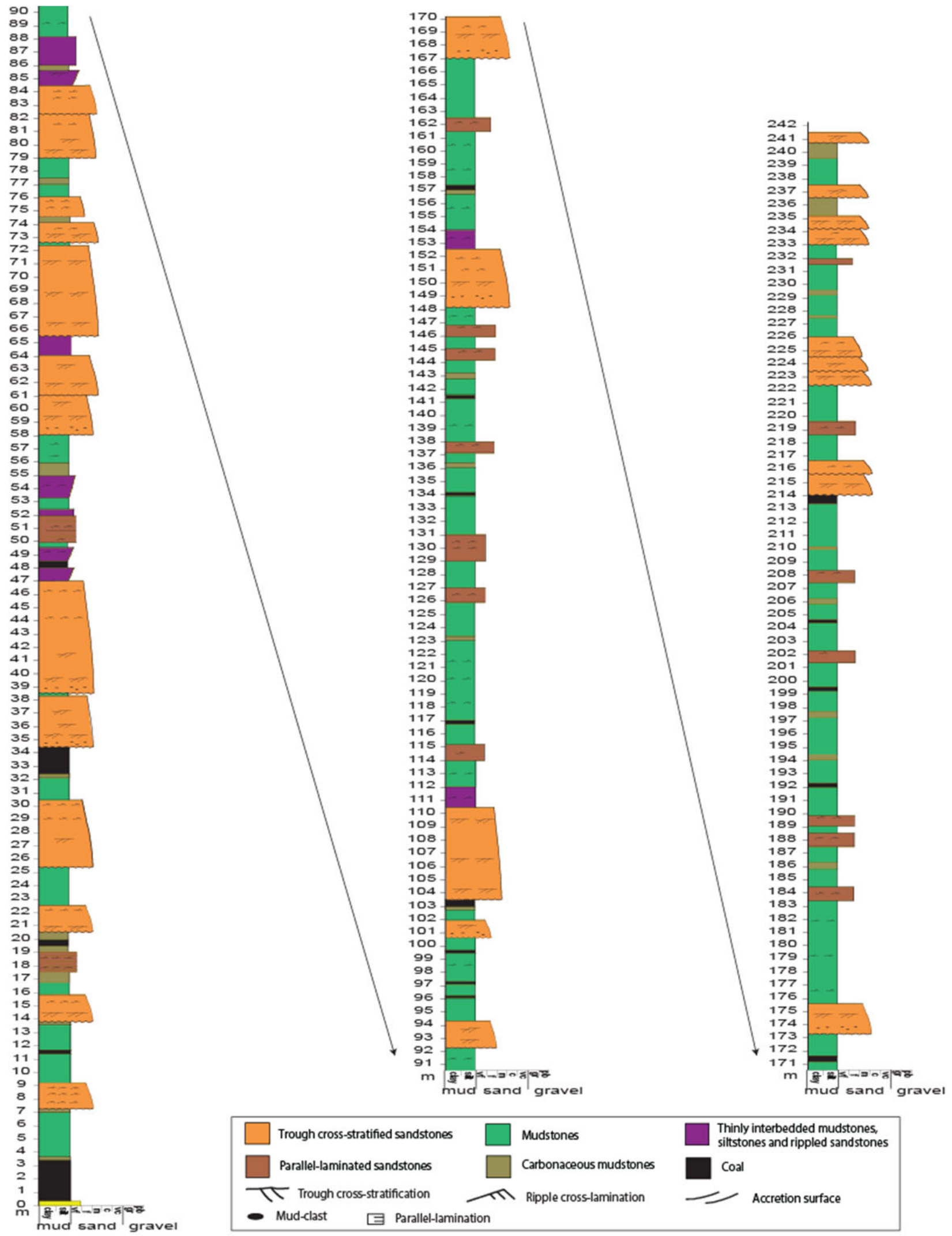

Figure S9. Detailed sedimentological description of the EM-137C core (located in Figs. 2B and 2C). 


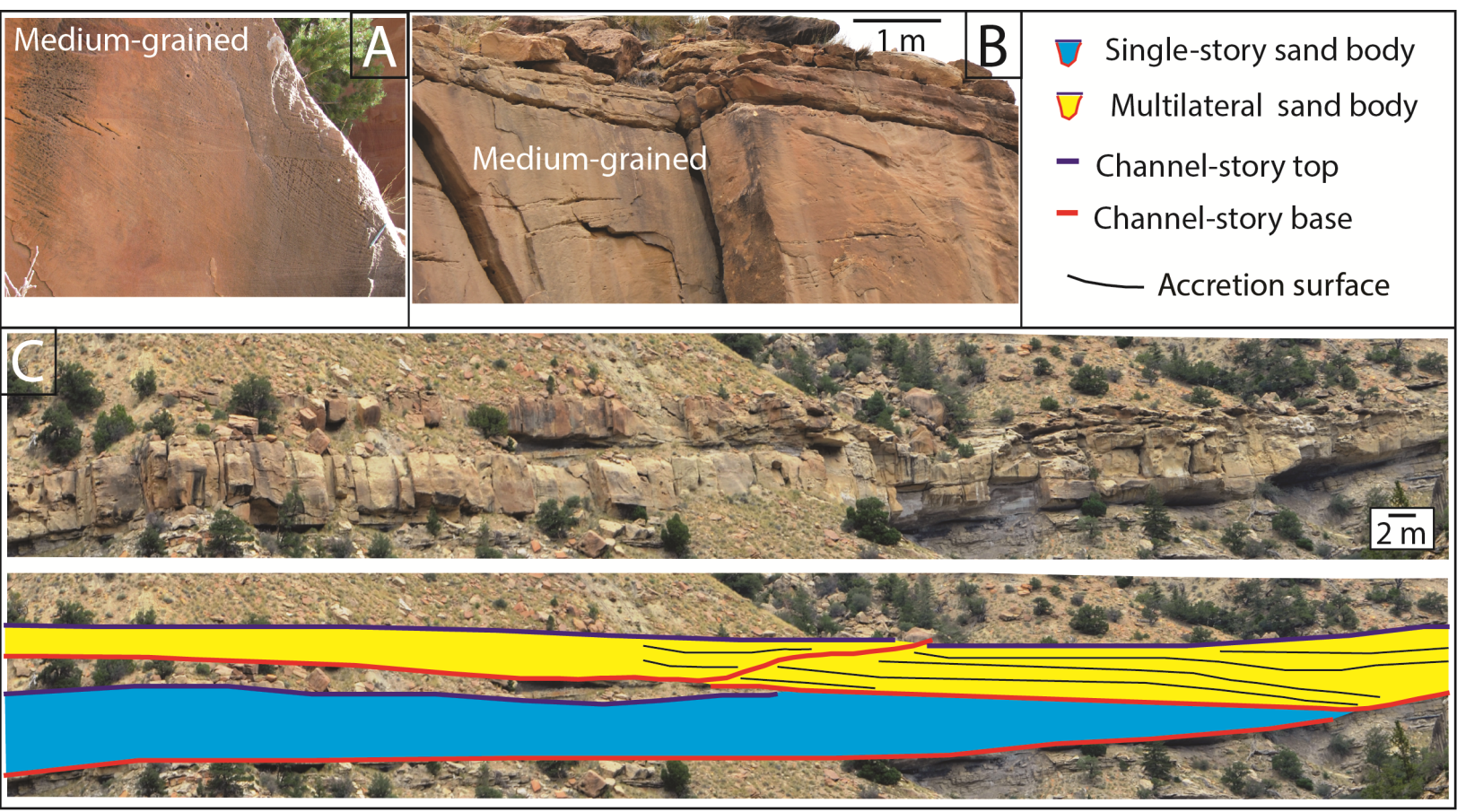

Figure S10. Outcrop characterization of sand bodies and their stratigraphic stacking pattern. See Figure

3A for the stratigraphic positions of the illustrated sand bodies. A) Part of multilateral sand body

(medium-grained) containing dune cross-stratification (Fig. 3A). B) Single-story sand body (medium-

grained) containing dune cross-stratification (Fig. 3A). C) Single-story sand body overlain by multilateral sand body in a sand-body cluster (Fig. 3A). Floodplain deposits are intercalated between underlying single-story sand body and overlying multilateral sand body.

\section{Paleohydraulic Analysis to Estimate Paleochannel Parameters}

The studied outcrops contain only one fully preserved paleochannel (Fig. S11B), which

142 provides little constraint on paleochannel dimensions. Therefore, we estimated paleochannel

extent of lateral-accretion bed, and bar height) and well-established paleohydraulic

relationships (cf., Hampson et al., 2013 and references therein; Gani and Gani, 2011 and references therein). Such paleohydraulic analysis of outcrop data has become a useful means of 
147 deriving paleochannel parameters (e.g., Hampson et al., 2013; Holbrook and Wanas, 2014;

148 Bhattacharya et al., 2016).

149

\section{$150 \quad$ 3.1. Flow-depth Estimation}

151 From compiled dune-scale cross-set thickness data, the mean cross-set thickness $\left(\mathrm{S}_{\mathrm{m}}\right)$ and 152 standard deviation $\left(S_{s d}\right)$ were calculated. When $S_{m} / S_{s d}$ is $\sim 0.88$, average dune height $\left(h_{m}\right)$ can be 153 estimated as (Le Clair and Bridge, 2001; Bridge and Tye, 2000):

$$
h_{m}=5.3 \beta+0.001 \beta^{2}
$$

$$
\beta \approx S_{m} / 1.8
$$

156 Flow-depth scales to 6-10 times the average dune height. Accordingly, the bankfull flow depth 157 of paleochannels was estimated.

Additionally, the bankfull flow depth of paleochannels was estimated from the thickness

159 of a fully preserved bar sand-body $\left(T_{h}\right)$ using the equation:

$$
\text { Bankfull flow depth }=\mathrm{T}_{\mathrm{h}} / 0.9 \text { (3) }
$$

161 Using the above two approaches, we have compiled estimates of bankfull flow depth for the 162 paleochannels forming single-story and multilateral sand bodies (Fig. 4C).

\subsection{Channel-width Estimation}

Bankfull channel width can be estimated as (Bridge and Mackey, 1993; Bridge and Tye, 2000):

$$
\mathrm{W}=8.88\left(\mathrm{~d}_{\mathrm{m}}\right)^{1.82}
$$

167 Where $d_{m}$ is the mean bankfull channel depth. Using Equation 4, we estimated bankfull width values of paleorivers forming single-story and multilateral sand bodies. 
Paleochannel-width values derived from paleohydraulic analysis of sand bodies at

170 different stratigraphic positions have a narrow range $(100-160 \mathrm{~m})$. The resulting mean

171 paleochannel width $(115 \mathrm{~m})$ is consistent not only with other mean values estimated for

172 paleochannels in nearby exposures of the Blackhawk Formation (Rittersbacher et al., 2014;

173 Hampson et al, 2013) but also with the directly measured value of $100 \mathrm{~m}$ of the preserved

174 abandoned-channel fill in the study data set (Fig. S11). Given this similarity, we estimated a final

175 mean value for paleochannel width of $106 \mathrm{~m}$ (Fig. S11A).

176

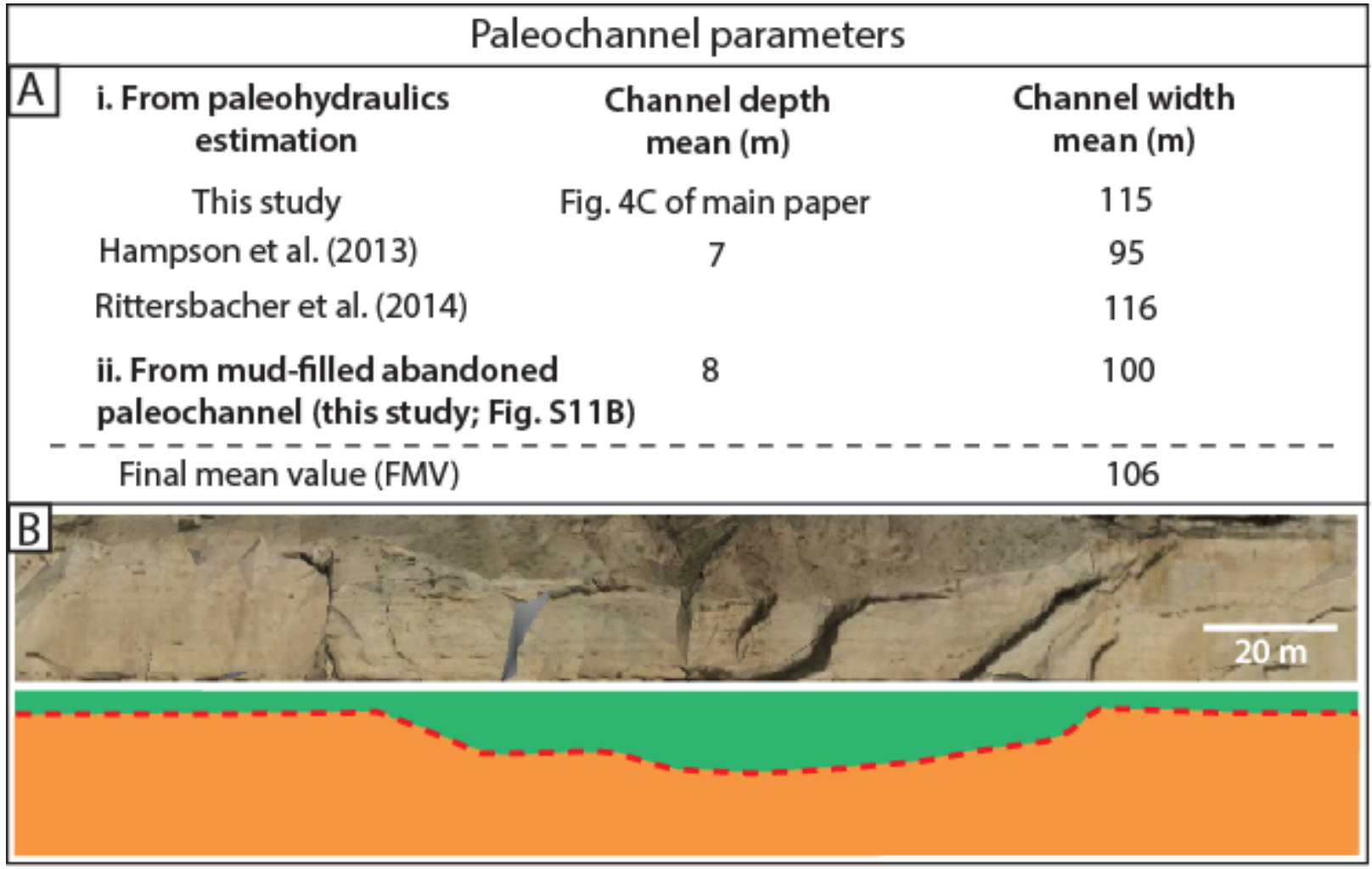

178 Figure S11. Derivation of paleochannel dimensions from paleohydraulic analysis in this study and 179 previous studies (A), and from direct measurement of abandoned-channel (B). 


\section{Channel-mobility Index (M)}

Channel mobility implies a rate, which has been quantitatively assessed in modern systems (e.g., Jerolmack and Mohrig, 2007; Blum et al., 2013). However, constraining rates from analysis of ancient strata is almost impossible, given the sparse sampling and low resolution of available age data, as has been pointed out by recent studies (e.g., Jobe et al., 2016). Jobe et al. (2016) instead used channel geomorphic expression (i.e., abandoned channel fills), paleohydraulic estimates, and sand-body dimensions to conduct mobility analysis in ancient strata (e.g., derivation of their 'stratigraphic mobility number'). Here we have taken a similar approach to channel mobility analysis in our data set, using channel geomorphic expression (i.e., abandoned channel fills; e.g., Fig. S11), paleohydraulic estimates (Section 3) and sand-body dimensions (Table S1).

We define channel mobility as the degree of lateral channel migration on the floodplain prior to avulsion (cf. Gibling, 2006; Jerolmack and Mohrig, 2007). To analyze this parameter, we develop a dimensionless channel-mobility index, $M$, where:

$$
M=\text { width of sand body / width of paleochannel }
$$

Here, 'width of sand body' denotes the near-true width calculated for each sand body (methodology described in Section 1.2, and values in Table S1), and 'width of paleochannel' is the final estimate of mean paleochannel width $(106 \mathrm{~m})$ that we derived from paleohydraulic analysis (methodology described in Section 3; Fig. S11). Since paleohydraulic analysis is used to estimate mean 'width of paleochannel', values of $M$ are indicative, and some physically unrealistic values $<1$ are calculated. $M$ provides a quantitative proxy of the extent to which a formative channel was laterally mobile with respect to its width, in depositing a sand body. 
204 Frequency distributions of $M$ values have been calculated for single-story and multilateral sand 205 bodies in the study data set (Figs. 4D and 4E).

206

We also performed a sensitivity test to evaluate how estimation of $M$ varies when using

207 final mean value $(106 \mathrm{~m})$ and extreme values of channel width (lowest $100 \mathrm{~m}$, and highest 160

$208 \mathrm{~m})$. M estimations for these three cases of channel width show only small variability (STD $=0.1-$

209 2).

210

211

212

213

214

215

216

217

218

219

220

221

222

223

224

225

226 


\section{Depocenter Shift from Multilateral Sand Body to Single-story Sand Body}

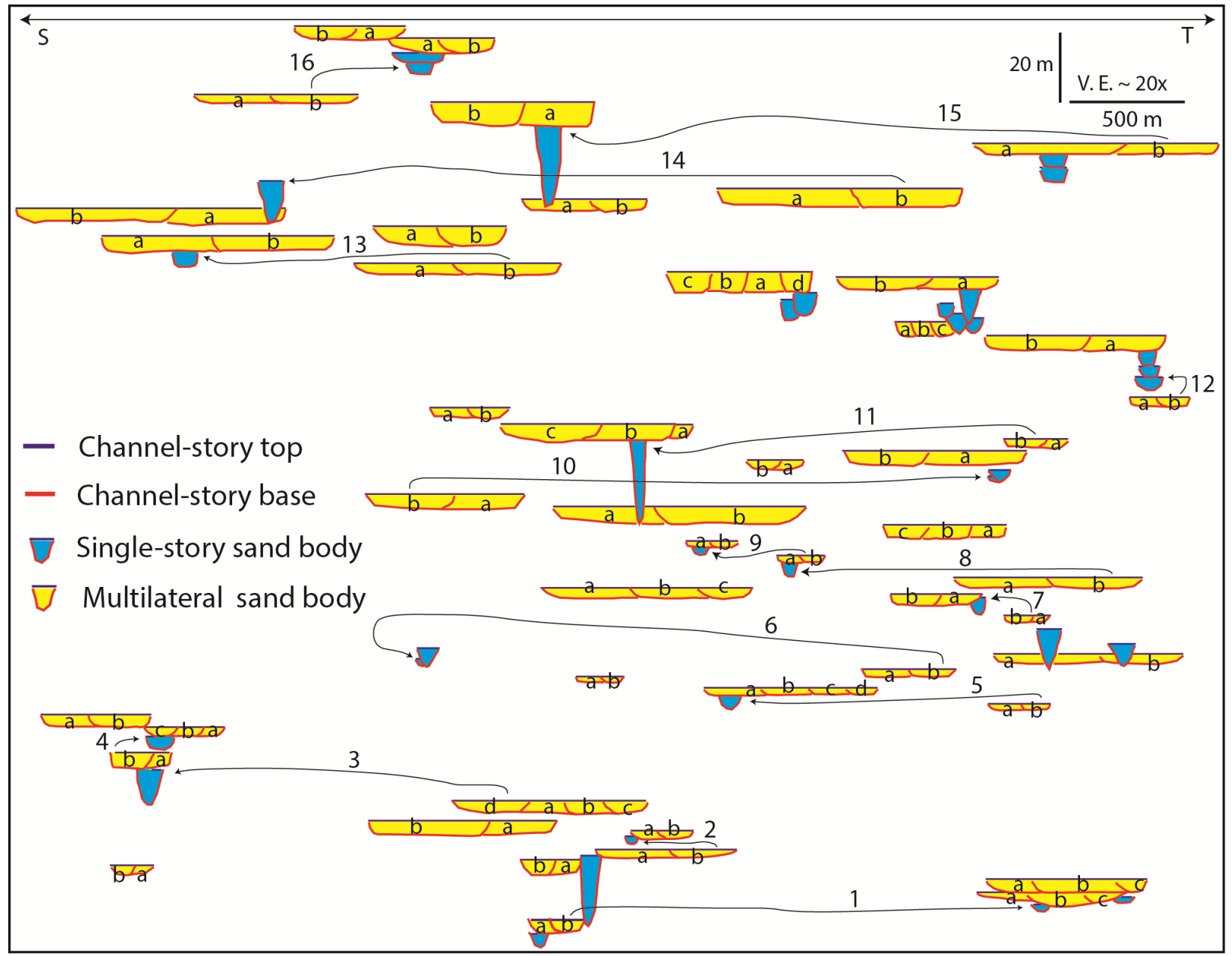

229

Figure S12. Examples $(n=16)$ on study data set, in which depocenter shifts stratigraphically from a multilateral (preceding sand body) to single-story (succeeding sand body), assuming that sand-body

231 relative age corresponds to height above the datum at the base of the transect (i.e., top of Star Point

232 Formation; Fig. S4). These examples illustrate an inferred compensational stacking pattern of sand 233 bodies, since the preceding multilateral sand bodies are not vertically stacked (no channel 234 reoccupation). 


\section{References}

Bhattacharya, J.P., Copeland, P., Lawton, T. F., and Holbrook, J., 2016, Estimation of source area, river paleo-discharge, paleoslope, and sediment budgets of linked deep-time depositional systems and implications for hydrocarbon potential: Earth-Science Reviews, v. 153, p. 77-110.

Blum, M., Martin J., Milliken, K., and Garvin, M., 2013, Paleovalley systems: Insights from Quaternary analogs and experiments: Earth-Science Reviews, v. 116, p. 128-169.

Bridge, J. S., and Tye, R. S., 2000, Interpreting the dimensions of ancient channel bars, channels, and channel belts from wireline-logs and cores: American Association of Petroleum Geologists Bulletin, v. 84, no. 8, p. 1205-1228.

Bridge, J. S, and Mackey, S. D., 1993, A theoretical study of fluvial sandstone body dimensions, in S. S. Flint and I. D. Bryant, eds., The geological modeling of hydrocarbon reservoirs and outcrop analogues: International Association of Sedimentologists Special Publication No. 15, p. 3-20.

Fabuel-Perez, I., Hodgetts, D., and Redfern, J., 2009, A new approach for outcrop characterization and geostatistical analysis of a low-sinuosity fluvial-dominated succession using digital outcrop models: Upper Triassic Oukaimeden Sandstone Formation, central High Atlas, Morocco: AAPG Bulletin, v. 93, p. 795-827.

Flood, Y.S., and Hampson, G.J., 2014, Facies and architectural analysis to interpret avulsion style and variability: Upper Cretaceous Blackhawk Formation, Wasatch Plateau, central Utah, USA: Journal of Sedimentary Research, v. 84, p 743-762.

Gani, M. R., and Gani, N. D., 2011, River-margin habitat of Ardipithecus ramidus at Aramis, Ethiopia 4.4 million years ago: Nature Communications 2, 602. doi:10.1038/ncomms1610.

Gibling, M.R., 2006, Width and thickness of fluvial channel bodies and valley fills in the geological record: a literature compilation and classification: Journal of Sedimentary Research, v. 76, p. 731-770.

Hampson, G. J., Jewell, T. O., Irfan, N., Gani, M. R., and Bracken, B., 2013, Modest change in fluvial style with varying accommodation in regressive alluvial-to-coastal-plain wedge: upper cretaceous Blackhawk Formation, Wasatch Plateau, central Utah, U.S.A.: Journal of Sedimentary Research, v. 83, p. 145-169.

Hampson, G. J., Gani, M. R., Sahoo, H., Rittersbacher, A., Irfan, N., Ranson, A., Jewell, T. O., Gani, N. D. S., Howell, J. A., Buckley, S. J., and Bracken, B., 2012, Controls on large-scale patterns of fluvial sandbody distribution in alluvial to coastal plain strata: Upper Cretaceous 
Blackhawk Formation, Wasatch Plateau, Central Utah, USA: Sedimentology, v. 59, p. 22262258.

Holbrook, J., and Wanas, H., 2014, A Fulcrum Approach To Assessing Source-To-Sink Mass Balance Using Channel Paleohydrologic Paramaters Derivable From Common Fluvial Data Sets With An Example From The Cretaceous of Egypt: Journal of Sedimentary Research, v. 84, p. 349-372.

Holbrook, J., Scott, R.W., and Oboh-ikuenobe, F.E., 2006, Base-level buffers and buttresses: a model for upstream versus downstream control on fluvial geometry and architecture within sequences: Journal of Sedimentary Research, v. 76, p. 162-174.

Jerolmack, D.J., and Mohrig, D., 2007, Conditions for branching of rivers: Geology, v. 35, p. 463466.

Jobe, Z.R., Howes, N. C., and Auchter, N. C., 2016, Comparing submarine and fluvial channel kinematics: Implications for stratigraphic architecture: Geology, v. 44, p. 931-934.

Le Clair, S.F., and Bridge, J.S., 2001, Quantitative interpretation of sedimentary structures formed by river dunes: Journal of Sedimentary Research, v. 71, p. 713-716.

Potter, P.E., 1967, Sand bodies and sedimentary environments: a review: American Association of Petroleum Geologists Bulletin, v. 51, p. 337-365.

Rittersbacher, A., Buckley, S.J., Howell, J.A., Hampson, G.J., and Vallet, J., 2013, Helicopterbased laser scanning: a method for quantitative analysis of large-scale sedimentary architecture, in Martinius, A.W., Howell, J. A., and Good, T., eds., Sediment-body Geometry and heterogeneity: Analogue studies for modelling the subsurface: Geological Society of London, Special Publication 387, published online first, unpaginated.

Sahoo, H., and Gani, N.D., 2015, Creating three-dimensional channel-bodies in Lidar-integrated outcrop characterization: A new approach for improved stratigraphic analysis: Geosphere, v. 11, p. 777-785, doi:10.1130/GES01075.1.

Sahoo, H., and Gani, M.R., 2016, Autogenic Modulation of Fluvial Channel Fills in Allogenically Formed Incised Valleys: Cretaceous Blackhawk Formation, USA, in Budd, D., et al., eds., Autogenic Dynamics and Self-Organization in Sedimentary Systems: Society for Sedimentary Geology (SEPM) Special Publication 106, p. 163-175. https://doi.org/10.2110/sepmsp.106.08.

Sahoo, H., Gani, M.R., Hampson, G.J., Gani, N.D., and Ranson, A., 2016, Facies-to sandbodyscale heterogeneity in a tight-gas fluvial reservoir analog: Blackhawk Formation, Wasatch Plateau, Utah, USA: Marine and Petroleum Geology, v. 78, p. 48-69. 